\title{
KEWAHYUAN NABI MUHAMMAD DALAM PANDANGAN ORIENTALIS
}

\author{
Budi Sujati \\ UIN Sunan Gunung Djati Bandung (budisujati@gmail.com)
}

\begin{abstract}
This paper departs from the issue of the apocalypse of the prophet Muhammad who received a diverse view of the orientalists in addressing the apocalypse of the prophet Muhammad. The attitude of the orientalists both the pros and cons is still a polemic that until now has not finished the point of the problem. Therefore, from among those who received the revelation of Muhammad thought that the revelation received by the prophet Muhammad is a revelation that really comes from the teachings of God is not from the results of the prophet Muhammad and his teachings are sourced from the one God. While those who give cynical comments about the revelation given to Muhammad is the result of Muhammad's own composition, thus generating a lot of polemic, especially from among Muslims who until now has not been resolved and become a debate. This paper seeks to prove that with the approach of Social Science and Humanities will be found a fact that the prophet Muhammad's revelation in the orientalist view must be in accordance with an event with full objective.
\end{abstract}

Keywords: Revelation, Orientalist, Muhammad, Islam

\begin{abstract}
Abstrak
Tulisan ini berangkat dari permasalahan kewahyuan nabi Muhammad yang mendapat pandangan beraneka ragam dari kalangan orientalis dalam menyikapi kewahyuan nabi Muhammmad. Sikap para orientalis baik yang pro dan kontra masih menjadi polemik yang sampai saat ini tidak selesai titik permasalahannya. Oleh karenanya, dari kalangan yang menerima kewahyuan Muhammad beranggapan bahwa wahyu yang diterima oleh nabi Muhammad adalah wahyu yang benar-benar datang dari ajaran Tuhan bukan dari hasil karangan nabi Muhammad dan ajarannya bersumber dari Tuhan yang satu. Sedangkan mereka yang memberikan komentar sinis mengenai wahyu yang diberikan kepada Muhammad adalah hasil karangan Muhammad sendiri, sehingga memunculkan banyak polemik khususnya dari kalangan umat Islam sendiri yang sampai saat ini belum dapat diselesaikan dan menjadi perdebatan. Tulisan ini berusaha membuktikan bahwa dengan pendekatan Ilmu sosial dan Ilmu humaniora akan ditemukan suatu fakta bahwa kewahyuan nabi Muhammad dalam pandangan orientalis harus sesuai dengan dari sebuah peristiwa dengan penuh objektif.
\end{abstract}

Kata Kunci: Wahyu, Orientalis, Muhammad, Islam.

\section{A. Pendahuluan}

Kemunculan agama Islam tidak terlepas dengan diutusnya Nabi Muhammad sebagai pembawa risalah bagi umat manusia. Bagi sebagian umat manusia, khususnya kalangan umat Islam, Nabi Muhammad mempunyai peranan yang sangat vital dan krusial dalam pelbagai macam aspek kehidupan, terutama dalam penyebaran agama Islam. Oleh karena itu, Nabi Muhammad SAW dibekali salah satu wahyu yang dikenal dengan sebutan 
Al-Qur'an. ${ }^{1} \quad$ Ia berfungsi sebagai pedoman pokok kehidupan umat manusia yang ada muka di bumi ini Al-Qur'an dan kitab-kitab tuhan lainnya merupakan jalinan utuh dimana semuanya berasal dari risalah yang universal dan identik serta berasal dari sumber yang tunggal. ${ }^{2}$ Oleh karena itu umat manusia harus mempercayai semuanya baik Islam, Yahudi dan Nasrani. Adanya hubungan tersebut, Nabi Muhammad SAW mengakui Nabi Nuh AS, Nabi Ibrahim AS, Nabi Musa AS, dan Nabi Isa AS serta kitab-kitabnya. ${ }^{3}$

Namun menurut pandangan Yahudi dan Nasrani yang sekarang, mereka memandang bahwa Nabi Musa dan Nabi Isa terlahir secara otomatis menjadi Nabi. Bahkan dalam tradisi ajaran kristen terbukti ada upaya untuk menutup-nutupi perkara kenabian Isa Al-Masih, di samping ada upaya-upaya perubahan

\footnotetext{
${ }^{1}$ Sebagai wahyu, Al-Qur'an bukan pikiran dan ciptaan Nabi Muhammad SAW. Oleh karena itu, mereka yang mengatakan bahwa Al-Qur'an itu pikiran dan ciptaan nabi Muhammad SAW tiidak benar dan tidak dapat dipertanggungjawabkan. Lihat (Q.S AlBaqarah[2];2), terbebas dari keraguan, (Q.S AnNaml [27];1), kecurangan, dan (Q.S AlSyuara[26];210), kejahilan. Lihat. Atang Abd Hakim, Jaih Mubarok, Metodologi Studi Islam,(Bandung, Remaja Rosdakarya, 2000), hlm. 72 .

${ }^{2}$ Lihat Q.S Az-Zuhruf [43];Ar'Ra'ad[13];39, AlWaqiah [56];78.

${ }^{3}$ Lihat Q.S Al-Syura [42];15.
}

yang dilakukan oleh Paulus dalam memodifikasi doktrin ajaran agama Kristen. Sehingga dalam ajaran agama Kristen terjadi kesulitan dalam menemukan teks perjanjian lama dalam suatu bahasa, yang bentuk dan isinya benar-benar dari langit (Tuhan). ${ }^{4}$

Dengan kesulitan dalam menemukan teks yang asli pada ajaran Nasrani dan Yahudi, Pada akhirnya Al-Qur'an adalah kitab suci universal yang memiliki daya tarik bagi para cendekiawan Muslim maupun non-Muslim untuk dikaji dan dipelajari, sekaligus ingin memberikan beberapa bukti bahwa tingkat orisinalitas Al-Qur'an sebagai wahyu Tuhan dalam mentransfer ajaran Tuhan menjadi ajaran manusia.

Ketertarikan cendekiawan muslim maupun non-Muslim pada Fenomena kajian agama Islam dikalangan pemikir Barat berbedabeda. Misalnya dikalangan orientalis yang menggunakan pisau analisis historis lebih banyak menyikapi Islam dengan negatif, contohnya dengan menganggap Islam tak lebih sekedar Bid'ah Kristen. Sedangkan pemahaman positif lebih banyak

\footnotetext{
${ }^{4}$ Ajid Thohir,Sirah Nabawiyah, (Bandung : Marja, 2014), hlm. 138.
} 
dilakukan oleh Islamolog ${ }^{5}$, misalnya Margaret Marcus (Maryam Jamilah). Titik pandang yang berbeda tersebut didasari atas perbedaan sudut pandang, pendekatan dan interpretasi yang dilakukan. Di sisi lain, terdapat pula pemahaman agama Islam khususnya aspek kewahyuan (AlQur'an) menurut sosiolog, humanis, sekuler, dan modernis Barat. ${ }^{6}$

Fokus utama yang menjadi ketertarikan para orientalis terhadap nila-nilai kewahyuan dalam Islam adalah sisa-sisa trauma dan dendam yang berkepanjangan yang tidak bisa dilupakan begitu saja sejarah antara Islam dan Kristen dimulai dari Pendudukan Andalusia (Spanyol), penaklukan Konstantinopel, dan Perang Salib. Mereka ingin menjauhkan umat Islam dari kewahyuan Tuhan (Al-Qur'an) sehingga menghasilkan umat Islam yang bimbang, ragu, skeptis yang pada akhirnya menjadikan Umat Islam lupa jati dirinya. Dengan begitu wahyu memandu ilmu akan

${ }^{5}$ Islamologi adalah ilmu yang mengkaji tentang keislaman berikut sejarah lahir dan perkembangannya. Lihat Pius Partanto, M. Dahlan Al Barry, Kamus Ilmiah Populer, (Surabaya: Arkola, 2001), hlm, 280.

${ }^{6}$ Muhammad Al-Fatih Suryadilaga, Jurnal Tsaqafah Vol. VII No. I, Kajian atas Pemikiran John Wansbrough tentang Al-Qur'an dan Nabi Muhammad, (Yogyakarta : UIN Sunan Kalijaga Yogyakarta,2011),hlm. 91. diganti dengan ilmu memandu wahyu.

Tulisan ini akan membahas pengaruh kewahyuan nabi Muhammad yang mendapat sambutan pro dan kontra dikalangan orientalis. Dengan pendekatan ilmu sosial dan ilmu humaniora akan menemukan sebuah jawaban sesuai dengan kondisi pada zamannya yang pada akhirnya tidak menimbulkan kesan dan pengaruh negatif terhadap Islam.

\section{B. Kewahyuan Nabi Muhammad}

Kata wahyu adalah bentuk masdar (infinitif) dari auha-yuhiwahyan. Dengan dua pengertian pokok yaitu (1). Al-khafa' (tersembunyi) dan (2). As-Sur'ah (cepat). Oleh sebab itu, secara etimologis wahyu didefinisikan sebagai berikut: "pemberitahuan secara tersembunyi dan cepat yang khusus ditujukan kepada orang yang diberitahu tanpa diketahui oleh orang lainnya. ${ }^{7}$ Sedangkan secara terminologi wahyu adalah pernyataan Allah yang diturunkan kepada para nabi atau para rasul-Nya

${ }^{7}$ Yunahar Ilyas, Kuliah ulumul Qur'an, (Yogyakarta : ITQAN Publishing, 2014), hlm. 17. 
untuk disampaikan kepada umatNya. $^{8}$

Ketika Nabi Muhammad tepat berusia 40 tahun, ditengah ibadahnya di gua Hira' sebagaimana beliau biasa melakukannya selama tiga tahun terakhir di bulan ramadhan, Allah SWT berkehendak memancarkan rahmatnya kepada penduduk bumi dan menghubungkan bumi dengan langit. Allah SWT mengutus malaikat Jibril untuk menyampaikan wahyu kepada nabi Muhammad. $^{9}$

Adapun cara Allah SWT menurunkan wahyu kepada nabi Muhammad adalah melalui beberapa cara sebagai berikut :

1. Malaikat memasukan wahyu kedalam hati nabi Muhammad

2. Malaikat menampaka dirinya kepada nabi Muhammad berupa seorang laki-laki

3. Malaikat menampakan dirinya kepada nabi Muhammad dalam rupanya yang asli

4. Wahyu yang datang kepada nabi Muhammad seperti gemerincing lonceng ${ }^{10}$

${ }^{8}$ Pius A Partanto, M Dahlan Al Barry, Op. Cit.,hlm. 787.

${ }^{9}$ Tim Riset dan studi Islam Mesir, Ensiklopedi Sejarah Islam Jilid I, (Jakarta : Pustaka Kautsar, 2005), hlm. 11.

${ }^{10}$ Atang Abd Hakim, Jaih Mubarok, Op.Cit., hlm. 75 .
Berkaitan dengan proses penyampaian wahyu kepada nabi Muhammad terdapat beberapa pendapat, diantaranya berasal dari sejumlah orientalis namun tidak begitu banyak, seperti orientalis yang telah masuk Islam yaitu Karen Amstrong, yang pernyataannya cukup menyinggung umat Islam. Ia mengatakan, "ketika tersadar, Muhammad begitu masygul memikirkan bahwa setelah semua upaya spiritualnya, beliau ternyata dirasuki jin sehingga tidak ingin hidup. Dalam keputusannya, beliau lari dari gua dan mulai mendaki ke puncak gunung untuk melontarkan dirinya hingga mati.

Mengomentari tulisan itu, Jalaludin Rahmat dalam pengantar buku "Muhammad" karya Karen Amstrong, mengatakan bahwa Karen Amstrong itu bersikap simpatik tetapi tidak kritis. Meski Amstrong memiliki reputasi baik sebagai pengamat Islam yang simpatik terhadap Islam, namun ia mantan biarawati, sehingga tidak bisa dilepaskan dirinya dari latar belakang kebudayaannya. ${ }^{11}$ Menurut analisis penulis, pendapat Karel Amstrong itu wajar karena dia tidak mengetahui secara kejadian secara kronologis dan historis sehingga

${ }^{11}$ Ajid Thohir, Op. Cit., hlm. 139. 
pendapatnya masih dipengaruhi oleh unsur-unsur setting masa lalunya.

Ketika wahyu yang diturunkan bersifat terputus nabi Muhammad hanya diam dalam keadaan termenung dan sedih. Kegelisahan melingkupi diri nabi. Dalam kitab At-Tabir, Imam Bukhari meriwatkan naskah sebagai berikut : Menurut berita yang sampai kepada kami, wahyu berhenti turun hingga membuat nabi sedih $^{12}$ dan berkali-

${ }^{12}$ Komentar : terdapat kekeliruan, dimana lafal "menurut berita yang sampai kepada kami, wahyu berhenti turun hingga membuat nabi sedih" dan selanjutnya dan selanjutnya merupakan tambahan Muammar pada riwayat Uqail dan Yunus. Penulis (Bukhari) mengira bahwa itu masuk dalam riwayat Uqail. AlHumaidi juga menulis seperti itu dalam buku Jam' $u$-nya, sehingga ia menulis hadits sampai ungkapan "dan wahyu pun terputus." Kemudian ia berkata, 'selesai hadits Uqail yang menyendiri dari Ibnu Syihab (Az-Zuhri) seperti yang disebutkan.' Al-Bukhari menambahkan darinya dalam hadits yang terkait dengan Muammar Az-Zuhri, ia berkata, (wafatru alwahyi fatratu hatta khazan) 'wahyu berhenti turun hingga membuat beliau bersedih.' Ia menyebutkan hingga akhir. Menurut Syafiyurahman Al-Mubarakfuri, tambahan ini khusus pada riwayat Muammar. Karena ia telah mentakhriz jalur Uqail Abu Nu'aim dalam mustakhrajnya, dari jalur Abu Zur'ah Ar-Razi, dari Yahya bin Bukair, guruAl-Bukhari didalamnya, diawal kitab disebutkan tanpa itu. Al-Bukhari mentakhrij sebagai pembanding disini dengan riwayat Muammar dan menjelaskan bahwa redaksi milik Muammar. Al-Ismaili juga menjelaskan bahwa tambahan itu dalam riwayat Muammar.

Imam Ahmad, Muslim, Al-Ismaili, Abu Nu'aim, dan selain mereka juga mentakhrijnya dengan cara penyatuan dari para perawi yang sejalur dengan Laitsi, dari Laitsi tanpa itu.
Kemudian, yang menurut kami dengar, yang mengatakan adalah Az-Zuhri . makna ucapan tersebut bahwa secara singkat cerita nabi Muhammad SAW sampai kepada kita dalam kisah ini merupakan kata-kata Az-Zuhri, bukan bersambung ke beliau. Al-Kirmani mengatakan, "inilah yang tampak bahwa kemungkinan AzZuhri menyampaikannya dengan sanad tersebut." Dan ini juga terdapat pada Ibnu Mardaweh di tafsirnya dari jalur Ibnu Katsir dari Muammar dengan membuang kata "menurut yang kami dengar". Redaksinya adalah : sekian lama nabi sedih karena terhentinya wahyu itu hingga akhir. Jadi, semuanya mengarah ke riwayat Az-Zuhri dan dari Urwah, dari Aisyah. Riwayat dari Az-Zuhri yang bisa dipercaya.

Al-Bani berkata didalam Ad-Dhifa'an Al-Hadits An-Nabawi wa As-Shirah, hal. 40-41, dikatakan bahwa, penisbatan kepada Bukhari ini merupakan kesalahan yang fatal karena dia meyakini bahwa kisah tidak pantas ini adalah shahih sesuai syarat Bukhari, padahal tidak demikian. Penjelasannya,bahwa Bukhari mengeluarkan di akhir hadits Aisyah RA dalam permulaan wahyu yang dipaparkan oleh Dr. AlButhi, padahal pada Bukhari berada di awal (At-Ta'bir); Fathul Bari, XII/297-304 dari jalur Muammar : Az-Zuhri berkata, "Urwah mengabarkan kepadaku dari Aisyah RA...lalu menyebutkan dari hadits tersebut hingga kalimat "wahyu berhenti". Az-Zuhri menambahkan : hingga menyebabkan nabi bersedih dan berkali-kali berlari ke gunung dan ingin menjatuhkan diri dari jurang, namun setiap mencapai puncak gunung untuk mencampakan dirinya, malaikat Jibril menampakan wujudnya sembari berkata, "wahai Muhammad, sesungguhnya engkau benar-benar utusan Allah !' motivasi ini dapat menenangkan dan memantapkan kembali jiwa beliau. Lalu pulanglah beliau kerumah, namun ketika wahyu tidak kunjung turun, beliau pun mengulangi tindakannya sebagaimana sebelumnya; dan ketika dia mencapai puncak gunung. Malaikat Jibril menampakan wujudnya dan berkata kepadanya seperti sebelumnya."

Muslim juga meriwayatkan dari jalur tersebut, namun tidak menyebutkan redaksi tersebut. Ia 
justru menyebutkan redaksi riwayat Yunus dari Ibnu Syaibah dan tidak ada tambahan tersebut didalamnya. Muslim dan Ahmar juga meriwayatkannya dari jalur Uqail bin Khalid: Ibnu Syihab menuturkan itu tanpa tambahan tersebut. Bukhari juga menyebutkannya pada permulaan As-Shahih dari Uqail dengan redaksi itu.

Saya (Al-Bani) katakan, kita dapat menyimpulkan dari uraian tersebut bahwa tambahan tersebut memiliki dua cacat : "pertama, Muammar menyendiri dalam periwayatan, tanpa ada kesamaan dengan Yunus dan Uqail. Maka ini syadz (Nyeleneh), dan kedua, sanadnya mursyal lagi mu'dhal. Karena yang mengucapkan "menurut yang kami dengar" adalah Az-Zuhri seperti yang terlihat jelas dari konteks dan dengan itu pula Al-Hafizh menegaskan di Al-Fath, XII/302, "itu merupakan penyampaian dari Az-Zuhri, dan tidak bersambung."

Saya (Al-Bani) katakan bahwa ini adalah sesuatu yang diabaikan oleh Dr. Al-Buthi atau tidak diketahuinya, sehingga ia mengira bahwa semua huruf (redaksi hadits) di Shahih Bukhari itu sesuai dengan syarah Bukhari dalam kesahihannya. Ia mungkin tidak membedakan antara hadits yang bersanad dan mu'alaq, sebagaimana ia juga tidak membedakan antara hadits maushul dan hadits mursal, yang disebutkan disitu secara langsung.Misalnya hadits Aisyah RA yang akhirnya ada tambahan mursal. Ketahuilah bahwa tambahan itu tidak berasal dari jalur yang bersambung, sehingga bisa dijadikan hujjah.

Al-Bani juga mengatakan di kitabnya, AlSilsilah Al-Hadits Adh-Dhaifah. Hadits no. 1053, "intinya, bahwa hadits ini dhaif dan tidak shahih, baik dari Ibnu Abbas maupun dari Aisyah RA. Karena itu, Al-Bani memperingatkan hal ini dalam koreksinya atas kitab Mukhtashar Shahih Bukhari, 1/5 bahwa penyampaian Az-Zuhri ini tidak sesuai syarah Bukhari, agar tidak ada satupun pembaca yang mengira itu shahih karena disebutkan didalam kitab As-Shahih. Lihat : As-Shilsilah Al-Hadits Adh-Dhaifah, Al-Bani, hadits no.4858; AsSirah An-Nabawiyah As-Shahihah, disertasi kali berlari ke gunung dan ingin menjatuhkan diri ke jurang, namun setiap nabi Muhammad mencapai puncak gunung untuk menampakan dirinya, malaikat Jibril menampakan wujudnya sembari berkata "wahai Muhammad, sesungguhnya engkau benar-benar utusan Allah!" motivasi ini dapat menenangkan dan memantapkan kembali jiwa beliau. Lalu pulanglah beliau kerumah, namun ketika wahyu tidak turun, beliau pun mengulangi tindakan sebagaimana sebelumnya; dan ketika dia mencapai puncak gunung, malaikat Jibril menampakan wujudnya dan berkata kepadanya seperti sebelumnya. ${ }^{13}$

Sikap yang sama dikemukakan oleh Philip K Hitti dijelaskan dalam bukunya History of the Arabs bahwa Muhammad sedang berada didalam gua hira' ia mendengar sebuah suara yang memerintahnya : "bacalah ! dengan nama Tuhanmu yang menciptakan," dan seterusnya. Itulah wahyu pertamanya. Peristiwa yang menandai munculnya seorang nabi penerima wahyu di tanah Arab. Malam terjadinya peristiwa itu kemudian dikenal sebagai "malam

Imad As-Sayyid Muhammad IsmailAsySyarbini,cet. Darul Yaqin.

13 Shaffiyurrahman Al-Mubarakfuri, sirah Nabawiyah,(Jakarta : Umul Qura, 2012), hlm.137-139. 
penuh keagungan" (lailatul qadar). ${ }^{14}$

Dalam merangkai sebuah penjelasan Philip K Hitti sangat objektif karena ia menyatakan hasil kajian sesuai dengan apa adanya. Berkaitan dengan hal tersebut ketika wahyu diturunkan bersifat terputus-putus atau berangsur-angsur terdapat hikmah untuk umat Islam dalam menjawab serangan yang datang dari kalangan yang menentang dan melemahkan para penentang AlQur'an khususnya orientalis yaitu sebagai bukti bahwa wahyu yang turun mengikuti setiap kejadian dalam menetapkan akidah yang benar, hukum-hukum syariat dan akhlak mulia. ${ }^{15}$

Mengingat wahyu adalah perintah Tuhan yang harus dibersihkan dari prasangkaprasangka negatif dari para orientalis. Disini perlunya sejarawan untuk memberikan sebuah pemahaman dengan menggunakan pendekatan-pendekatan yang berkaitan dengan ilmu sosial dan ilmu humaniora.
C. Orientalisme

dan

\section{perkembangannya}

Orientalisme, terdiri dari dua kata, yaitu oriental dan isme. Oriental: bersifat timur, sedangkan isme: paham dan ajaran. Maka orientalisme dapat diartikan "paham dan ajaran yang bersifat timur". Yakni, mengetengahkan masalahmasalah timur. ${ }^{16}$

Orientalisme berasal dari kata orient, bahasa Perancis, yang secara harfiah bermakna timur. Dan secara geografis bermakna dunia belahan timur. Secara etnologis bermakna bangsa-bangsa di timur. Oriental adalah hal-hal yang bersifat timur, sedangkan orientalis adalah kata nama pelaku yang menunjukkan seseorang yang ahli tentang hal-hal yang berkaitan dengan "timur" (ahli ketimuran). Dan kata "isme" (Belanda) ataupun "ism" (Inggris) menunjukkan pengertian tentang suatu paham. Jadi orientalisme bermakna sesuatu paham atau aliran, yang berkeinginan menyelidiki halhal yang berkaitan dengan bangsabangsa timur beserta lingkungannya. ${ }^{17}$

\footnotetext{
${ }^{14}$ Philip K Hitti, penj. Cecep Lukman Yasin, History of the Arabs, (Jakarta : Serambi ilmu semesta, 2013), hlm. 141.

${ }^{15}$ Rosihan Anwar, Pengantar Ulumul Qur'an, (Bandung : Pustaka Setia, 2013), hlm. 50.
}

16 Ahmad Sa'di Al Farinduany, Orentalisme Pertumbuhan dan Perkembangan,(Surabaya : Pustaka Progresif, 1988), hlm. 8.

17 H.M. Joesoef Sou'yb, Orientalisme dan Islam, (Jakarta : Bulan Bintang, 1995), hlm. 1. 
Ada tiga istilah yang berkaitan dengan orientalisme. Ketiga istilah itu adalah:

1. Orient, berarti wilayah timur, bangsa Timur atau kebudayaan Timur. Kata ini berlawanan dengan istilah Occident yang artinya barat, bangsa Barat atau kebudayaan Barat.

2. Orientalis, adalah pada sarjana atau ahli tentang ketimuran. Mereka ini mempelajari budaya ketimuran. Mereka terdiri dari filolog, sosiolog, antropolog, linguism saintist dan juga teolog. Awalnya adalah studi ilmiah yang bersifat objektif dan akademis. Namun sulitnya tujuan mulia itu kemudian diboncengi dengan kepentingan yang tidak baik misalnya kapitalisme yang muaranya menjadi koloni-alisme.

3. Orientalisme, kata ini berasal dari kata Orient (timur) dan isme (paham). Jadi orientalisme adalah ideologi atau paham ketimuran. Dari pengertian itulah maka orientalisme mempunyai banyak pengertian.

Orientalisme adalah suatu gaya berfikir yang berdasarkan pada pembedaan ontologis dan epistemologis yang dibuat antara "Timur" (the Orient) dan "Barat" (The Occident). Dalam makna lain "Orientalisme" merupakan suatu gerakan yang timbul di zaman modern, pada bentuk lahirnya bersifat ilmiah, yang meneliti dan memperdalam masalah ketimuran. Tetapi di balik penelitian masalah ketimuran itu mereka berusaha memalingkan masyarakat Timur dari Kebudayaan Timurnya, berpindah mengikuti keinginan aliran Kebudayaan Barat yang sesat dan menyesatkan. ${ }^{18}$

Penyebab langsung munculnya orientalis atau ahli ketimuran adalah adanya studi-studi yang dilakukan oleh ilmuwan Barat tentang ketimuran. Minat orang Barat meneliti masalah-masalah ketimuran sudah berlangsung lama sejak Islam berkuasa di Andalusia (Spanyol) pada abad ke-8 Masehi. Mereka melahirkan sebuah karyakarya yang menyangkut masalah ketimuran. Dalam rentang waktu antara abad kemunculan Islam sampai abad ini, secara garis besar orientalisme dapat dibagi tiga periode, yaitu (1) masa keemasan zaman Islam (650-1250); (2) masa perang salib sampai masa pencerahan di Eropa dan

${ }^{18}$ Edward W. Said,Orientalisme,(Yogyakarta : Pustaka Pelajar, 1994), hlm.3. 
munculnya masa pencerahan di Eropa sampai sekarang. ${ }^{19}$

\section{Masa Keemasan Dunia Islam}

Pada zaman keemasan dunia Islam, negeri-negeri Islam khususnya Baghdad sebagai Pusat peradaban Islam bagian Timur dan Andalusia (Spanyol) sebagai pusat peradaban Islam bagian Barat menjadi pusat peradaban ilmu pengetahuan. Bangsa-bangsa Eropa yang menjadi penduduk asli Andalusia menggunakan bahasa Arab sebagai bahasa komunikasi dan adat-istiadat Arab dalam kehidupan sehari-hari. Mereka menuntut ilmu di perguruanperguruan tinggi Arab. Sejarah mencatat bahwa diantara raja-raja Spanyol yang non Muslim ada yang hanya mengenal huruf Arab misalnya : Peter I (w. $1140 \mathrm{M}$ ) raja Aragon. Raja Alfonso IV mencetak mata uang dengan huruf Arab. Hal ini sama dengan raja Sicilia, raja Normandia, Roger I menjadikan istananya sebagai tempat para filosof, dokter-dokter, dan ahli Islam lainnya dalam berbagai ilmu pengetahuan. Keadaan ini berlanjut sampai raja Roger III. Dimana pakaian kebesarannya digunakan pakaian Arab, bahkan gerejanya dihiasi dengan ukiran Arab. Wanita

19 Dewan Redaksi Ensiklopedi Islam, Ensiklopedi Islam Jilid IV, (Jakarta : PT. Ichtiar baru Van Hoeve, 1999), hlm. 55.
Kristen Sicilia meniru wanita Islam dalam berbusana.

Peradaban Islam itu bukan hanya berpengaruh bagi bangsa Eropa yang berada dibawah atau bekas kekuasaan Islam, tetapi juga bagi orang Eropa diluar daerah itu. Penuntut ilmu dari Prancis, Inggris, Jerman dan Italia datang belajar ke perguruan dan universitas yang ada di Andalusia dan Sicilia. Diantara mereka ituadalah pemuka-pemuka kristen misalnya Gerbert d'Aurillac yang belajar di Andalusia dan Adelard dari Bath (1107-1135) yang belajar di Andalusia dan Sicilia. Gerbert d'Aurillac kemudian menjadi Paus di Roma dari tahun 999-1003 dengan nama Silvester II. Adapun Adelard setelah kembali ke Inggris diangkat menjadi guru pangeran Henry yang kelak menjadi raja. Ia menjadi salah satu penerjemah buku-buku Arab kedalam bahasa latin. ${ }^{20}$

Dalam suasana inilah muncul orientalisme dikalangan Barat. Bahasa Arab mulai dipandang sebagai bahasa yang harus dipelajari dalam bidang ilmiah dan filsafat. Pelajaran bahasa Arab dimasukan kedalam kurikulum diberbagai perguruan tinggi di Eropa, seperti di Bologna (Italia) pada tahun 1076,

\footnotetext{
${ }^{20}$ Ibid., hlm. 56.
} 
Chartes (Prancis) tahun 1117, Oxford (Inggris) tahun 1167, dan Paris (Prancis) tahun 1170. Munculah generasi pertama, Constantinus Africanus (w. 1087) dan Gerard Cremonia (w. 1187).

Tujuan orientalisme pada masa ini adalah memindahkan ilmu pengetahuan dan filsafat dari dunia Islam ke Eropa. Tujuan ini meningkatkan minat mereka dalam mempelajari bahasa Arab di universitas-universitas. Di Italia bahasa Arab diadakan di Roma (1303), Florence (1321), Padua (1361), dan Gregoria (1553); di Inggris dilaksanakan di Cambridge tahun (1209), sedangkan di Eropa dimulai abad ke-15.

\section{Masa perang Salib sampai masa pencerahan di Eropa}

Perang Salib antar umat Islam Timur dan Kristen Barat yang menghabiskan tenggang waktu antara tahun 1096-1291 membawa kekalahan dan kerugian bagi Kristen. Namun demikian tidak berarti umat Islam tidak menderita. Akibat perang salib putra-putra terbaik bangsa gugur dimedan tempur. Aset-aset dan kekayaan negara berupa sarana dan prasarana pada saat itu, banyak mengalami kehancuran. Kemiskinan, dekadensi moral dan kebodohan terjadi akibat perhatian para pemimpin terfokus pada pertahanan kekuasaan dari serangan tentara salib. Oleh karena itu, umat Islam tidak mendapatkan keuntungan apapun dari perang salib, selain kehancuran. Sebaliknya, meskipun umat Kristen dinyatakan kalah, tetapi kontak Islam-Kristen ini mempunnyai sumbangsih yang sangat besar terhadap lahirnya renaissance kemajuan peradaban ilmu pengetahuan di Eropa setelah bangsa Eropa tenggelam dalam kegelapan. ${ }^{21} \quad$ Padaperiode awal perang salib ini, dibentuklah studi Islam untuk tujuan misi pada abad ke-12 pada masa Peter Agung (sekitar 1094-1156), kepala biara pria Cluny di Prancis yang hingga saat ini menjadi lembaga utama pengetahuan Kristen. Pada tahun 1142 Peter sebagai kepala lembaga mengadakan perjalanan ke Andalusia (Spanyol) untuk mengunjungi biarabiara Clunic. Pada saat inilah Peter memutuskan untuk melakukan sebuah proyek besar untuk melibatkan beberapa penerjemah dan sarjana, untuk memulai studi sistematis tentang Islam. Ketika Peter memberikan otoritas untuk penerjemahan dan penafsiran teksteks Islam yang berbahasa Arab terjadilah cerita-cerita cabul tentang Muhammad. Cerita itu melukiskan

${ }^{21}$ Harun Nasution, Islam Rasional; gagasan dan pemikiran. (Bandung : Mizan, 1995), hlm. 302. 
Muhammad sebagai tuhan, pendusta, penggemar wanita, seorang Kristen yang murtad, tukang sihir dan sebagainya. $^{22}$

Korpus (kumpulan naskah) Cluniac yang dikenal sebagai usaha Peter ini, menjadi standar pengetahuan kesarjanaan Barat tentang Islam pada saat itu. Banyak teks Islam yang berbahasa Arab diterjemahkan termasuk Al-Qur'an, Hadits, biografi nabi (Sirah) dan teks opologetik "opologi Al-Kindi" yang memuat perdebatan antara Kristen dan Muslim yang terjadi pada Khalifah Al-Makmun (813-833). Karya Al-Kindi ini sangat populer di kalangan sarjana Kristen pada abad pertengahan karena memberikan model argumentasi tentang Islam. Fokus serangan-serangan ini khususnya adalah Al-Qur'an, kenabian Muhammad, dan penyebaran agama melalui penaklukan (jihad). Tiga topik ini merupakan fokus utama dalam telaah para sarjana Kristen tentang Islam pada abad Pertengahan.

Dalam situasi sosial politik ini, ternyata aktifitas penerjemahan jauh lebih menarik di Eropa Kristen. Pada akhir abad ke-12 muncul sebuah karya paripatetik muslim Ibnu Shina

22 John L. Esposito. Terj. Eva Y.N Dkk. Ensiklopedia Oxford Dunia Islam Modern Jilid III, (Bandung : Mizan, 2001), hlm. 2. dan beredar di Eropa. Semakin banyaknya karya filosofis dan ilmiah diterjemahkan dari bahasa Arab ke bahasa Latin, para sarjana Eropa pada akhir abad pertengahan memandang dunia Muslim kontemporer sebagai peradaban sarjana dan filosofis, yang sangat kontras dengan popularitas pandangan menghina nabi Muhammad dan praktik religius Islam. Sebab lain yang menyebabkan dunia Islam dihormati adalah kesuksesan militer dan diplomasi Ayyubiyah, Shalahudin terhadap perang Salib. Sehingga kaum Kristen, baik dari kalangan sarjana, maupun pendeta pada saat itu saling menghormati, juga mengamati sikap dan praktek religius yang shaleh dari umat Islam.

\section{Masa Pencerahan di Eropa sampai Sekarang}

Ketegangan antara Kristen dan Islam yang timbul akibat adanya tulisan-tulisan negatif dari para orientalis yang dialamatkan kepada Islam dan umat Islam mulai mereda setelah memasuki masa pencerahan (enlightenment) yang diawali dengan mencari kebenaran. Sikap positif ini muncul akibat adanya perubahan religius, politik, dan intelektual yang mendalam pada reformasi pada abad ke-16. Pada masa pencerahan ini kekuatan rasio mulai meningkat, dimana sebuah tulisan yang 
dibutuhkan adalah objektif, bukan mengada-ada. Mulailah muncul karya-karya mengenai Islam mengandung serangan-serangan dan menjelek-jelekan, dan ada juga penghargaan terhadap nabi Muhammad SAW dan Al-Qur'an serta ajaran-ajarannya. ${ }^{23}$

Sepanjang zaman keemasannya pada abad ke-19, orientalisme telah melahirkan banyak cendekiawan, telah meningkatkan jumlah bahasa-bahasa yang diajarkan di Barat dan jumlah manuskripmanuskrip yang disunting, diterjemahkan, dan ditafsirkan. Dalam banyak hal, orientalisme telah memberikan (kepada Timur) pengkaji-pengkaji Eropa yang simpatik, yang benar-benar tertarik pada masalah-masalah seperti tatabahasa sansakerta, huruf paku Funisia, dan Syair Arab.

Namun demikian, disini Edward W Said berbicara tegas. Orientalisme telah mencapai berbagai prestasinya yang luar biasa itu, kajian ini ternyata tetap tidak bisa untuk tidak melangkahi Timur secara angkuh dan menghina. Misalnya saja, pengamatan dari seorang orientalis terhadap seorang pujangga Arab abad ke-10 yang

23 Abd Rahim, Sejarah Perkembangan Orientalisme., (Palu : Jurnal Hunafa STAIN Datokarama, 2010), hlm. 188. entah tanpa landasan yang memadai seketika berubah dan melipatgandakan diri menjadi politik terhadap mentalitas Timur di Mesir, Iraq, atau Arabia. Begitu pula, hanya karena para orientalis mengutip satu ayat saja dalam Al-Qur'an dalam mendeskripsikan Islam, orang Eropa akan menganggapnya sebagai bukti yang terbaik dari sensualitas Islam yang sudah mendarah daging. ${ }^{24}$

Kegiatan-kegiatan

para orientalis meliputi : (1) mengadakan kongres-kongres secara teratur yang dimulai di Paris (1873) dan di kotakota lain di dunia secara bergantian. Kongres-kongres pada mulanya bernama Orientalits Congres. Sejak tahun 1870 dan telah berganti nama menjadi Internasional Congress on Asia and Norrth Africa; mendirikan lembaga-lembaga kajian ketimuran, di antaranya Ecole des Langues Orientalis Vivantes (1975) di Perancis, the Schooll of Ariental and African Studies, Universitas London, (1917) di Inggris, Oosters Institut (1971) di Universitas Amsterdam; (3) mendirikan organisasi-organisasi ketimuran, misalnya Societe Asiatique (1822) di Paris, American Oriental Society (1842) di Amerika Serikat, Royal Asiatic Society di Inggris, dan Oosters Genootschap in Nederland

\footnotetext{
${ }^{24}$ Edward W. Said, Loc,. Cit. hlm. 144.
} 
(1929) di Leiden; dan (4) menerbitkan majalah-majalah, di antaranya Jurnal Asiatique (1822) di Paris, Journal of the Royal Asitic Society (1899) di London, Journal of the American Oriental Society (1849) di Amerika Serikat, Revaue du Monde Musulman (1907) di Perancis, Der Islam- Zeustschrift fur Gesehichte und Kultur des islamiscen (1919) di Jerman, The Muslim World (1917) di Amerika Serikat, dan Bulletin of the School of Oriental an African (1917) di London. Majalah-majalah ini sebagian besar tertib sampai sekarang.

Pada awalnya orang Kristen mempelajari agama Islam hanya sebatas untuk mengambil ilmu pengetahuannya saja seperti pada masa berkuasanya dinasti Andalusia di Spanyol. Namun pada perkembangannya, orientalis tetap membawa aroma sinis dan phobia terhadap Islam. Sehingga, mengakibatkan lembaga pengkajian orientalisme menjelma menjadi kebohongan-kebohongan yang memutarbalikan fakta terhadap ajaran Islam antara lain memfitnah nabi Muhammad SAW, menginterpretasikan Al-Qur'an sesuka mereka, memodernisasi hukum Islam, menghidupkan kembali ajaran jahiliyah serta menghidupkan nasionalisme kelompok Islam.

D. Pro Kontra Orientalis seputar Kewahyuan Nabi Muhammad

\section{Orientalis yang Pro}

Dalam menghadapi gejala historis yang serba kompleks, setiap penggambaran atau deskripsi menuntut adanya pendekatan yang memungkinkan penyaringan data yang diperlukan. Dalam hal ini Pendekatan yang digunakan dalam memahami wahyu agar seseorang memahami lebih komprehensif salah satunya dengen pendekatan fenomenologi. Pendekatan ini memiliki dua karakteristik : pertama; fenomenologi sebagai metode memahami agama, dalam konteks ini kewahyuan Nabi Muhammad. ${ }^{25}$

Dengan kata lain, fenomenologi adalah tindakan meninggalkan diri sendiri dan berusaha menghidupkan pengalaman orang lain. Kedua; karakter fenomenologi mampu mengkonstruksi rancangan taksonomi sehingga dapat mengklasifikasikan fenomena masyarakat beragama khususnya aspek kewahyuan dalam agama Islam. Dalam hal ini, fenomenologi mengumpulkan data sebanyak

${ }^{25}$ Sartono Kartodirjo, Pendekatan Ilmu Sosial dalam Metodologi Sejarah, (Yogyakarta : Ombak, 2017), hlm. 5. 
mungkin, lalu mencari kategori yang memiliki kesamaan yang pada intinya mencari struktur dalam pengalaman beragama untuk prinsipprinsip yang lebih luas, yang tampak dalam membentuk keberagaman manusia secara menyeluruh. ${ }^{26}$

Dalam hal ini orientalis yang simpati terhadap aspek kewahyuan nabi Muhammad bisa dilihat dari pembelaaan Maryam Jamilah (nama Aslinya Margaret Marcus) terhadap para orientalis dalam bukunya Islam dan Orientalisme. Menurutnya salah satunya mengenai keajaiban (mu'jizat) Al-Qur'an bukan hanya terletak pada asal-usul dan isinya tetapi juga pada bentuknya. Bagaimana mungkin orang yang tidak pernah memperoleh pendidikan dapat mencipta suatu karya tulis yang bukan hanya tidak ada tandingannya dan tidak dapat ditiru semacam itu? Bahkan seandainya manusia dan jin bersama-sama membuatnya pun, mereka tidak akan mungkin bisa mencipta kitab semacam itu. Nabi Muhammaddiberi senjata oleh Allah SWT untuk menentang orang-orang yang mengkritiknya agar mereka mencoba membuat satu surat saja yang mirip dengan Al-Qur'an. Tantangan

\footnotetext{
${ }^{26}$ Arfan Muammar, Abd Wahid Hasan. Dkk, studi Islam persfektif Outsider/insider, (Yogyakarta : IRCiSoD, 2012), hlm. 89-90.
}

tersebut sebagaimana diduga tidak pernah bisa dilumpuhkan dengan berhasil. Yang pasti ketika AlQur'an dibaca, melalui nada, irama, dan kata-katanya, ia dapat mencipta efek yang setengah hipnotis kepada para pendengarnya, walaupun mereka tidak memahami artinya. Dampaknya jelas lebih besar mengenai emosi dan imajinasi manusia dari pada pikirannya. ${ }^{27}$

Hal tersebut membantah tulisan orientalis Philips $\mathrm{K}$ Hitti dalam bukunya yang berjudulIslam and the West, ${ }^{28}$ bahwa nabi Muhammad SAW adalah seorang penipu lihai. Uraian yang dikemukakannya tentang kehidupan beliau mem- berikan kesan kepadanya bahwa dia telah benarbenar merencanakan tulisan itu secara cermat.

Kemudian mengenai ajaran Islam adalah ajaran yang rasional dengan menyatakan bahwa di dunia ini merupakan ladang untuk menanamkan benih dan dunia (akhirat) adalah tempat menuai dimana orang dapat menikmati buah dari pekerjaannya dibumi. Dengan

\footnotetext{
27 Maryam Jamilah, Penj. Machnun Husein, Islam dan Orientalisme, (Jakarta : Raja Grafindo Persada, 1997), hlm. 16-17.

${ }^{28}$ Lihat. Philip K Hitti, Islam and the West : An Historical, cultural survey, (Princeton : Van Norstad co, 1962), hlm. 63.
} 
perkataan lain, kehidupan sekarang ini merupakan satu-satunya untuk memperoleh kenikmatan Allah melalui iman dan amal shaleh. Dan semua kesempatan ini berakhir selama-lamanya pada saat kematian kita. Manusia berlomba-lomba dalam hal kebajikan.

Maryam Jamilah membantah prasangka buruk Dr. Kenneth Cragg dalam memahami pengertian hari kiamat yang dikemukakan AlQur'an, karena dikatakannya 'tidak menganggap kebahagiaan yang sempurna sebagai landasan dan pengertian yang tinggi." Terkait hal itu, ia menulis, dalam ajaran Islam tidak ada perkembangan pemikiran dalam ibadah maupun dalam cara bertaubat.

Maryam Jamilah juga mengemukakan bukti langsung mengenai asal-usul Al-Qur'an dari pada Allah SWT itu terlihat jelas dibagian Al-Qur'an itu sendiri. Hal itu ditunjukan juga dengan gejalagejala [kisah-kisah] khusus [asbabun nuzul] yang terjadi berbarengan dengan peristiwa turunnya AlQur'an tersebut. Peristiwa-peristiwa yang terjadi pada diri nabi setiap kali menerima wahyu, sebagai saksi objektif berupa tanda misterius yang dapat diamati, diperhatikan dan dibaca menunjukan secara jelas sumber asli Al-Qur'an itu untuk membuka setiap mata pencari kebenaran.

Dalam hal ini Maryam Jamilah membantah Orientalis yang menganggap Islam hanyalah versi agama Yahudi yang penuh distorsi. Seperti yang dikemukakan oleh Herman Cohen menurutnya ajaran mengenai kesalehan monastik yang tercakup dalam Al-Qur'an sudah ada dalam beberapa bentuk pada agama Yahudi kuno. ${ }^{29}$

Pemikiran-pemikiran Orientalis yang sangat sinis terhadap Islam mendapatkan kritikan dari Maryam Jamilah. Khususnya berkaitan dengan kemampuan nabi Muhammad dalam membaca sebuah teks Al-Qur'an ketika wahyu pertama kali diturunkan. Ia mengkritik tulisan Theodore Noldeke dengan mengemukakan fakta-fakta bahwa agama Islam bukan produk dari agama Nasrani atau Yahudi tetapi agama yang diturunkan oleh Allah untuk mengembalikan akidah bangsa Arab yang saat itu menganut agama Politeisme untuk kembali kepada ajaran monoteisme. Pada waktu itu nabi Muhammad tidak mengenal ajaran agama Yahudi dan Nasrani karena ia tidak bisa menulis dan membaca. Bagaimana mungkin

\footnotetext{
${ }^{29} \mathrm{Ibid}$, . hlm. 66.
} 
dengan keterbatasan kemampuan itu bisa memahami dan mendalami ajaran agama sebelumnya.

Adalah Theodore Noldoke ingin membuktikan bahwa apa yang diyakini umat Islam selama ini adalah salah. Ia meyakini bahwa AlQur'an tidak orisinal. Muhammad bukanlah seorang yang ummi, melainkan ia sangat akrab dengan seni menulis yang saat itu dianggap sebagai derajat orang yang berilmu,maka dari itu, nabi Muhammad mampu untuk menduplikasi agama-agama terdahulu. Ia menyatakan bahwa ajaran yang ia bawa bukanlah merupakan produk dirinya sendiri, melainkan adalah produk yang ia ambil dari Kristen dan Yahudi.Ia berasumsi bahwa pada saat masa kenabian Muhammad, kaum Yahudi sudah banyak yang tinggal di jazirah Arab, khususnya di Yatsrib (Madinah). Mereka mempunyai hubungan baik dengan Makkah dan sering mengunjunginya, dan bahkan dalam teologi Kristen pun banyak sekali disusupi ajaran-ajaran dari Yahudi. Maka menurutnya, tidak mustahil kalau dalam Islam pun banyak sekali ajaran yang mengadopsi dari Yahudi. ${ }^{30}$
Menurut Maryam Jamilah kebanyakan kritikan sinis dari orientalis tersebut mereka (orientalis) melangkah terlalu jauh dari batasbatas yang benar dan berusaha menafsirkan Islam dan peristiwaperistiwa yang terjadi di dunia Islam berdasarkan pandangan-pandangan pribadi yang tidak sesuai. Bahkan hingga memasuki ranah memberikan solusi kepada muslim bagaimna seharusnya mereka memecahkan persoalan-persoalan dan apa yang seharusnya dilakukan terhadap agama mereka.

Menurutnya lagi, orien-talisme bukan kajian objektif dan tidak memihak Islam, yang diupayakan secara mendalam bukan untuk mendapatkan hasil yang orisinil dan objektif tapi hanya rencana jahat yang terorganisasikan untuk menghasut para pemuda untuk memberontak terhadap agama mereka. Dalam konteks ini, Islam dikutuk hanya karena ia bertentangan dengan pandangan materialis yang berlakudanberlawanan dengan teori evolusi. $^{31}$

\section{Orientalis yang kontra}

Kiranya perlu ditekankan lagi bahwa semua penjelasan sejarah harus didukung oleh data otentik,

\footnotetext{
${ }^{30} \mathrm{http}$ //khalilkanzu.blogspot.co.id/2017/03/pem ikiran-theodor-noldeke-terhadap-al.html. diakses tgl 05 Februari 2018. Pukul.19:00
}

${ }^{31}$ Maryam Jamilah, Loc. Cit,. hlm. 195-196. 
terpercaya dan $\operatorname{tuntas}^{32}$. Dengan begitu, seseorang dalam memahami peristiwa akan memahami peristiwa tersebut dari asal-usul kemunculannya, sebab-akibat yang dari persoalannya sehingga mampu memahami suatu pokok persoalan dengan objektif.

Namun persoalannya adalah mereka dalam memahami aspek kewahyuan dengan menggunakan pendekatan Historisisme. Dalam kajian ini adalah suatu metode pendekatan kesejarahan yang berusaha mencari asal-usul Islam dan Al-Qur'an dari tradisi agama dan kitab suci sebelumnya. Dalam hal ini kelompok subjektif adalah kelompok yang pandangan dan penilaiannya sangat subjektif, tidak jujur, dan tendensius. Dengan kata lain, mereka menolak kewahyuan nabi Muhammad. Melalui pendekatan ini, ada beberapa hal yang menjadi perhatian sorotan orientalis, yaitu : ${ }^{33}$

Ali Shina ${ }^{34}$ salah satu tokoh orientalis yang sangat benci kepada

${ }^{32}$ Kuntowijoyo, Penjelasan Sejarah (Historical Explanation) (Yogyakarta : Tiara Wacana, 2008), hlm. 10.

${ }^{33}$ Ajid Thohir, Loc,. Cit.,hlm. 145.

${ }^{34}$ Ali Shina adalah warga negara Kanada keturunan Iran. Shina menerima pendidikan Islam di sekolah saat negara Iran masih sekuler dan kebangkitan Islam. Ia meninggalkan Iran sewaktu remaja sebelum terjadinya revolusi
Nabi Muhammad. Dia menulis sebuah buku Understanding Muhammad; a psichobiography. Didalamnya diceritakan suatu hari, ketika Muhammad berusia 40 tahun, dan menghabiskan waktu berharihari disebuah gua seorang diri, Muhammad mengalami pengalaman yang aneh. Dia mulai mengalami kontraksi otot, sakit perut, dan merasa seperti dihimpit kuat , kejang-kejang otot, kepala dan bibir bergerak-gerak diluar kontrol, berkeringat dan jantung berdebardebar. Dalam keadaan ini dia mendengar suara-suara dan mengaku melihat hantu. Dia lari kerumah ketakutan, gemetar dan berkeringat. “tutupi aku, tutupi aku', pintanya kepada istrinya. O Khadijah, ada apa dengan diriku ? dia menceritakan semua yang terjadi dan berkata, "aku takut sesuatu terjadi pada diriku". Dia mengira kerasukan setan lagi. Khadijah menenangkannya dan mengatakan padanya untuk tidak merasa takut. ${ }^{35}$

Kemudian di jelaskan bahwa nabi Muhammad sering mencoba bunuh diri, namun selalu diberhentikan oleh Jibril. Ia tadinya menyangka bahwa ia telah menjadi

Islam Iran 1979 untuk melanjutkan pendidikan tinggi di Eropa.

35 Ali Sina, Terj. Team Translator FFI. Memahami Muhammad: sebuah Psikobiografi. (Jakarta : Team FFI, 2010), hlm. 23. 
seorang penyair atau seorang juru nujum. Muhammad menggambarkan Jibril sebagai memiliki 600 sayap. Buraq kuda yang ditumpanginya pada malam ia terbang ke Yerusalem dan ke Surga, memiliki kepala manusia dan sayap burung rajawali. Kecuali orang yang bersedia percaya dalam absurditas ini, jelaslah Muhammad sedang halusinasi. ${ }^{36}$

Kemudian Ali Shina menafsirkan Al-Qu'ran surah At Taubah ayat 29"Perangilah orangorang yang tidak beriman kepada Allah dan tidak (pula) kepada hari kemudian dan mereka tidak mengharamkan apa yang telah diharamkan oleh Allah dan RasulNya dan tidak beragama dengan agama yang benar (agama Allah), (yaitu orang-orang) yang diberikan Al Kitab kepada mereka, sampai mereka membayar jizyah dengan patuh sedang mereka dalam keadaan tunduk”. (QS 9:29).

Menurut Ajid Thohir Dengan ayat itulah Ali Shina menuduh bahwa Nabi Muhammad menganjurkan umat Islam agar memerangi setiap orang nonIslam. Padahal arti sebenarnya ayat tersebut sangat jauh dari anggapan Ali Shina. Dalam menafsirkan Al-Qur'an terutama yang berkaitan dengan tema

\footnotetext{
${ }^{36}$ Ibid, hlm. 108.
}

tertentu maka kita harus mengumpulkan semua ayat AlQur'an yang berbicara tentang tema tersebut agar tidak terjadi kesalahan dalam menafsirkan. Tafsir ini disebut Tafsir tematik atau maudhui yang kami anggap merupakan tafsir yang paling baik. Kesalahan Ali Shinaadalah dia mengabaikan ayat Al-Qur'an yang menjelaskan siapa orang yang harus diperangi orang Islam dan siapa yang tidak. Penjelasan tentang hal ini terdapat dalam Al-Qur'an surah Al Mumtahanah ayat 8 dan 9 "Allah tidak melarang kamu berbuat baik dan adil terhadap orang-orang yang tidak memerangi kamu dalam agama dan tidak mengusir kamu dari kampung-kampungmu sebab Allah senang kepada orang-orang yang adil. Allah hanya melarang kamu bersahabat dengan orang-orang yang memerangi kamu dalam agama dan mengusir kamu dari kampungkampungmu dan saling bantumembantu untuk mengusir kamu, barangsiapa (berusaha) bersahabat dengan mereka maka mereka itu adalah orang-orang yang zalim". (QS 60:8-9).

Sudah jelas dari ayat di atas bahwa mereka yang harus diperangi orang Islam adalah orang-orang nonIslam yang memerangi orang Islam. Ketika zaman Rasulullah SAW mereka adalah kaum kafir 
Quraisy dan yang membantu kafir Quraisy dalam memerangi Rasulullah SAW dan pengikutnya. Mereka kaum kafir Quraisy telah menyakiti orang-orang islam dan mengusir orang-orang islam dari kampung halaman mereka. Mereka inilah yang dimaksud dalam AlQur'an surah At Taubah ayat 29 seperti yang dikutip ali sina itu. Sedangkan Al-Qur'an surah $A l$ Mumtahanah ayat 8 dan 9 dengan jelas menyatakan bahwa kita harus berbuat baik dan berlaku adil kepada orang nonIslam yang tidak memerangi umat Islam dalam agamanya.

Jadi penafsiran Ali Shina itu adalah salah sama sekali keliru, Islam tidak mengajarkan kekerasan kepada orang non-Islam, Islam mengajarkan agar pemeluknya memerangi orang nonIslam yang memerangi Islam dan berusaha menjatuhkan agama Islam atau mereka yang menyakiti dan menindas orang Islam. Sedangkan untuk orang nonIslam yang berhubungan baik dengan Islam, maka Islam mengajarkan agar pemeluknya berbuat baik dan berlaku adil terhadap mereka. Semua ini jelas menunjukkan toleransi yang baik dan adil dalam agama Islam. Tidak seperti yang dikatakan makhluk bernama ali sina itu.
Permasalahan Jizyah yang disinggung Ali Shina itu tidaklah bersifat buruk. Jelas sekali Ali Shina tidak mengerti Pemerintahan Islam dan aturannya. Dalam Pemerintahan Islam zaman Rasulullah SAW tidak ada itu yang namanya pajak. Oleh karena itu mereka orang non Islam yang bernaung di bawah pemerintahan Islam harus membayar jizyah sebagai balas jasa perlindungan yang diberikan pemerintah Islam. Setelah mereka membayar jizyah maka orang nonislam berhak diperlakukan dengan adil sama seperti orang muslim lainnya. Mereka orang nonislam yang membayar jizyah akan mendapat perlindungan dari Pemerintah Islam terhadap harta dan nyawa mereka. Orang muslim memang tidak membayar jizyah tetapi mereka yang muslim diwajibkan membayar zakat demi kepentingan masyarakat Islam. Sudah jelas orang nonmuslim tidak diwajibkan membayar zakat. Jadi dalam Pemerintahan Islam baik muslim dan nonmuslim jelas diperlakukan secara adil. ${ }^{37}$

Para Orientalis beranggapan bahwa wahyu yang diterima oleh

\footnotetext{
${ }^{37}$ https://antifaithfreedom.wordpress.com/2007/ 09/02/menjawab-tuduhan-ali-sina-bahwa-islammelakukan-kekerasan-kepada-orangnonmuslim/.com. Diakses 05 Februari 2018. Pukul 12.00
} 
Nabi Muhammad sebenarnya merupakan sebuah hasil dari pengadopsian dari berbagai tradisi Yahudi, Kristen, dan Persia. Begitu juga dalam artikel J. Bryan, yang sedikit menceritakan bagaimana proses Nabi Muhammad SAW mendapatkan wahyunya : "Mohammad dalam tahun-tahun awal, memiliki kesamaan dengan para pedagang Mekah, akrab dengan ajaran adat yang melingkupi berbagai doktrin yang diajarkan oleh tokoh Ibrani, sebuah bangsa yang baik, dalam bentuk yang tidak jelas dan membingungkan. Ia telah mempelajari sebagian hal ini dalam kabilah dagangnya yang ke Suriah, dan dalam beberapa kunjungannya ke pertemuan-pertemuan syair, nenek moyang Welsh Eisteddfod, yang diadakan secara rutin di Okadh dan kota-kota lainnya, di mana masalah-masalah keagamaan dibicarakan secara terbuka". Ia mendapatkan pengetahuan yang lebih jelas dan dalam dari kaum Hanif, sebuah lembaga kecil yang beranggotakan para pencari kebenaran, warga Mekah, dan para pelajar tentang Judaisme dan Kristen yang tekun. Ia karenanya terbina untuk menolak pemberhalaan dan menerima formula monoteistik yaitu formula La Ilaaha Illallah... Banyak ayat Mekah di dalam Al-Quran ditasbihkan kepada kisah Nabi, diambil dari sumber-sumber Ibrani. $^{38}$

Sedangkan menurut orientalis kontemporer Robert Spencer ${ }^{39}$ Salah satu tantangan terberat terhadap klaim Muhammad sebagai seorang Nabi, baik selama 23 tahun karirnya dan disepanjang sejarah Islam, adalah ketergantungannya yang sangat jelas terlihat pada Yahudi, Kristen dan sumber-sumber lainnya. Menurutnya sepanjang sejarah Agama Islam telah memperhatikan antara Islam dan Yudaisme,

38 Muhammad Basir, Pandangan Kaum Orientalis Terhadap Islam, (Yogyakarta : Bentang, 2003), hlm. 211.

${ }^{39}$ Lahir 27 Februari 1962, adalah pengarang dan narablog Amerika Serikat yang dikenal karena kritiknya terhadap Islam dan penelitian tentang terorisme Islam dan jihad. Ia telah menerbitkan dua belas buku, termasuk dua buku laris versi New York Times yaitu "The Truth about Muhammad: Founder of the world's most Intolerant religion". Tahun 2003, ia mendirikan Jihad Watch, blog yang katanya berisi berita seputar jihad Internasional, dengan tujuan menarik perhatian publik terhadap peran yang dimainkan teologi dan ideologi jihad di dunia modern, serta memperbaiki kesalahkaprahan umum seputar peran jihad dan agama dalam konflik masa kini. Ia juga ikut mendirikan Stop Islamization of America (SIOA) dan Freedom Defense Initiative bersama narablog Pamela Geller. Ia dan Geller juga menulis sebuah buku, The Post-American Presidency: The Obama Administration's War on America. Spencer dan Geller sampai sekarang dilarang masuk Britania Raya karena mendukung "grup kebencian antiMuslim". Lihat juga: https://id.wikipedia.org/wiki/Robert_Spencer_( pengarang). 
termasuk monoteisme "murni", urutan nabi-nabi, proliferasi hukum, arah ke kiblat suci saat bersembahyang, dan banyak lagi. Tidak diragukan lagi nabi Muhammad mempunyai kontak ekstensif seorang pemuda penjiplak walaupun secara moral nabi nMuhammad menghormati mereka dan berusaha mendapatkan restu mereka untuk mendapatkan misi profetisnya. Kenyataannya

nabi Muhammad menempatkan dirinya sendiri setara didalam sejarah keselamatan orang Yahudi. Dalam rekaan Al-Qur'an, nabi Muhammad adalah nabi terakhir dan terbesar disepanjang jajaran para nabi yang juga terdapat dalam Alkitab dan kitab-kitab lainnya. Setelah setan menipu Adam dan Hawa sehingga berpaling dari kebenaran (sebuah kisah yang langsung dikutip dari kitab kejadian, dengan modifikasimodifikasi dan penambahanpenambahan penting). ${ }^{40}$

Selanjutnya Ignaz Goldziher merupakan orientalis yang lebih menekankan penelitiannya terhadap Al-Qur'an. Pendekatan kajian Goldziher terhadap Al-Qur'an tidak sebatas mempertanyakan otoritasnya, namun isu klasik yang selalu

40 Robert Spencer, Terj. NN, Kebenaran Tentang Muhammad: Pendiri agama paling tidak toleran di dunia. (Jakarta : Tanpa penerbit, 2012), hlm. 45. diangkat adalah soal pengaruh Yahudi, Nasrani, Zoroaster dan sebagainya terhadap Islam dan isi kandungan Al-Qur'an. ${ }^{41}$

Goldziher berusaha mengungkapkan apa saja yang bisa dijadikan bukti bagi teori peminjaman dan pengaruh hal tersebut terutama dari literatur dan tradisi Yahudi-Nasrani, dan membandingkan ajaran Al-Qur'an dengan adat-istiadat Jahiliyah, Romawi, dan lain sebagainya. Goldziher mengatakan bahwa ceritacerita dalam Al-Qur'an banyak yang keliru dan tidak sesuai dengan versi Bible yang dianggap akurat. ${ }^{42}$ dapun tujuannya dalam mengkaji Islam adalah untuk mencemarkan akidah Islam dan meragukan Al-Qur'an. Hal ini terlihat dalam berbagai karyanya, secara lantang Goldziher mengatakan bahwa Islam cenderung lebih dekat dengan Judaisme (paham-paham dalam agama

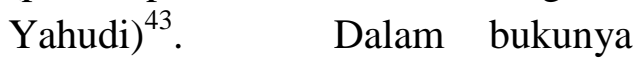
yang membahas qira'at, Goldziher dianggap telah melakukan penyimpangan yang sangat jauh, mengabaikan petunjuk yang benar, dan dengan sengaja mementahkan

${ }^{41}$ Syamsudin Arif, Orientalis dan Diabolisme Pemikiran, (Jakarta :Gema Insani Press, 2008), hlm. 7.

${ }^{42}$ Ibid., hlm. 8.

${ }^{43}$ Ibid.,hlm. 10. 
kebeneran Al-Qur'an. ${ }^{44}$ Menurut Goldziher, terkait dengan Al-Qur'an banyak perbedaan dalam hal qira'at dan tidak konsisten dalam hal tafsirnya dan ingin mengubah susunan ayat dan surat dalam AlQur'an secara kronologis, mengoreksi bahasa Al-Qur'an ataupun mengubah redaksi sebagian ayat-ayatnya.

\section{E. Penutup}

Islam tidak terlepas dari peran Nabi Muhammad sebagai seorang pembawa risalah kewahyuan, oleh karena itu Nabi Muhammad dibekali sebuah risalah kewahyuan yang dikenal dengan Al-Qur'an. Wahyu yang berupa Al-Qur'an tersebut sebagai risalah dan pelengkap bagi ajaran-ajaran sebelumnya. Dengan kemunculan Islam yang membawa risalah kewahyuan tersebut banyak mendapat sambutan baik dari kalangan sarjana muslim maupun non Muslim. Dari kalangan sarjana muslim mereka mempercayai sepenuhnya bahwa aspek kewahyuan adalah salah satu perintah yang harus ditaati dan dipercayai dengan sepenuh hati, karenanya mereka termasuk kubu yang mendukung

${ }^{44}$ Syekh Abdul Fattah Abdul Ghani al-Qadli. Semarang. Terj. Sayyid Agil Husain Munawar dan Abdul Rahman Umar, Bacaan Al-Qur'an dimata Orang kafir dan Atheis,(Semarang : PT. Karya Toha Putra, TT), hlm. 9. (bersikap pro) dengan kewahyuan nabi Muhammad. Sedangkan dari sarjana non-Islam, sebagian besar memandang bahwa aspek kewahyuan nabi Muhammad adalah sebuah hasil dari pemikiran nabi Muhammad sendiri. Mereka meyakini bahwa hal-hal itu digali dan diadopsi dari ajaran-ajaran agama sebelumnya, yakni agama Yahudi dan agama Nasrani. Mayoritas dari sarjana non Muslim adalah mereka yang menolak (bersikap kontra) dengan aspek kewahyuan nabi Muhammad.

Dengan adanya dikotomi di antara pihak yang pro dan kontra tersebut, timbul kajian tersendiri khususnya di kalangan sarjana nonMuslim yang melahirkan sebuah kajian orientalisme. Kelahiran orientalisme tersebut tidak terlepas dari sejarah panjang berkembangnya agama Islam yang menyebar ke pelbagai tempat dan mendapat penolakan atau tantangan dari agama Kristen. Dengan adanya perkembangan umat Islam yang semakin massif, eksistensi dan kondisi mereka pun semakin terdesak. Di beberapa tempat, kaum muslim yang semula merupakan minoritas berhasil menjelma menjadi mayoritas penduduk. Oleh karena latar belakang seperti itu lah, kemudian banyak bermunculan lembaga-lembaga pengkajian 
ketimuran (orientalism) di dunia Barat sebagai media bagi mereka untuk mempelajari pelbagai sisi orang-orang muslim dan timur yang semakin hari semakin berkembang, di samping menjadi lembaga untuk memelajari kelemahan umat Islam sendiri dari sudut pandang keimanan sehingga umat Islam menjadi ragu, bimbang dan skeptis.

Dengan bermunculannya lembaga-lembaga tersebut kemudian lahirlah beberapa tokoh orientalis yang menyerang secara membabi buta seluruh ajaran Islam dengan cara mendiskreditkan, memutarbalikan fakta, berpendapat subjektif, tendensius, dan sinis. Oleh karenanya sebagai seorang sejarawan, setidaknya kita dapat mencoba memberikan gambaran khususnya mengenai aspek kewahyuan secara objektif, yang berdasarkan peristiwa dan realita yang benar-benar terjadi pada masanya.

\section{Daftar Pustaka}

Buku:

Abbas, Siradjuddin, K.H., 40 Masalah Agama Jilid III, Cetakaan Kesebelas, di Cetek oleh PT. Karya Nusantara Bandung, dan Diterbitkan oleh Pustaka Tarbiyah, Jakarta, 1985.

Abd Hakim, Atang, Mubarok, Jaih. 2000. Metodologi Studi Islam. Bandung: Remaja Rosda karya.

Al-Mubarokfuri, Shaffiyurrahman. 2012. Sirah Nabawiyah. Jakarta : Umul Qura.

Anwar, Rosihon. 2013.Pengantar Ulumul Qur'an. Bandung : Pustaka Setia.

Arif, Syamsuddin. 2008. Orientalis dan Diabolisme Pemikiran. Jakarta : Gema Insani Press.

Basir, Muhammad. 2003. Pandangan Kaum Orientalis Terhadap Islam. Yogyakarta: Bentang.

Dewan Redaksi Ensiklopedi Islam. 1999 .Ensiklopedi Islam Jilid IV.Jakarta : PT. Ichtiar baru van Hoeve.

Esposito, John L. Terj. Eva Y.N Dkk. 2001. Ensiklopedi Oxford Dunia Islam Modern Jilid III. Bandung : Mizan.

Hitti, Philip K penj. Cecep Lukman Yasin. 2013. History of the Arabs. Jakarta : Serambi Ilmu semesta. 
Philip K Hitti, 1962. Islam and the West : An Historical, cultural survey. Princeton : Van Norstad co.

Ilyas, Yunahar. 2014. Kuliah ulumul Qur'an. Yogyakarta : ITQAN Publishing.

Jamilah, Maryam. Penj. Machnun Husein. 1997. Islam dan Orientalisme. Jakarta : Raja Grafindo Persada.

Kartodirdjo, Sartono. 2017. Pendekatan Ilmu Sosial dalam Metodologi Sejarah. Yogyakarta : Ombak.

Kuntowijoyo. 2008. Penjelasan Sejarah (Historical Explanation). Yogyakarta : Tiara Wacana.

Muammar, Arfan. Abd Wahid Hasan. Dkk. 2012. Studi Islam persfektif

Outsider/insider. Yogyakarta: IRCiSoD.

Nasution, Harun. 1995. Islam Rasional; gagasan dan pemikiran. Bandung : Mizan.

Partanto, Pius, M. Dahlan Al Barry. 2001. Kamus Ilmiah Populer. Surabaya : Arkola.

Rahim, Abdu. 2010.Sejarah Perkembangan Orientalisme. Palu : Jurnal Hunafa STAIN Datokarama.
Robert Spencer, Terj. NN. 2012. Kebenaran Tentang Muhammad: Pendiri agama paling tidak toleran di dunia.Berita Muslim Shahih.

Said, Edward W. 1994. Orientalisme. Yogyakarta : Pustaka Pelajar.

Sa'di Al Farinduany, Ahmad. 1988. Orentalisme Pertumbuhan dan Perkembangan. Surabaya : Pustaka Progresif.

Sina, Ali, Terj. Team Translator FFI. 2010. Memahami Muhammad: sebuah Psikobiografi. TT.

Sou'yb, H. Muhammad. Joesoef. 1995. Orientalisme Dan Islam. Jakarta BulanBintang, 1995.

Suryadilaga, Muhammad Al-Fatih. 2011. Kajian atas Pemikiran John Wansbrough tentang AlQur'an dan Nabi Muhammad. Yogyakarta: Jurnal Tsaqafah Vol. VII.

Thohir, Ajid. 2014. Sirah Nabawiyah.Bandung : Marja.

Tim Riset dan studi Islam Mesir. 2005. Ensiklopedi Sejarah Islam Jilid I. Jakarta : Pustaka Kautsar. 
Internet:

https://antifaithfreedom.wordpress.c om/2007/09/02/menjawabtuduhan-ali-sina-bahwaislam-melakukan-kekerasankepada-orang- nonmuslim/.com. Diakses 05 Februari 2018. Pukul 12.00.

http://khalilkanzu.blogspot.co.id/201 7/03/pemikiran-theodornoldeke-terhadap-al.html.

Diakses 05 Februari 2018. $\underline{\text { Pukul 19:00 }}$ 